\title{
KARAKTERISTIK DAN PENGGUNAAN ANTIBIOTIK PASIEN SEPSIS DI RUMAH SAKIT ABDUL WAHAB SJAHRANIE PERIODE 2017
}

\author{
Diana Anugrah Lestari*, ViriyanataWijaya, Hadi Kuncoro \\ Laboratorium Penelitian dan Pengembangan Kefarmasian "Farmaka Tropis", \\ Fakultas Farmasi, Universitas Mulawarman, Samarinda, Indonesia \\ *Email: danugrahlestari@gmail.com
}

\begin{abstract}
Sepsis is a medical condition characterized by inflammation throughout the body in response to infections caused by SIRS (Systemic Inflammatory Response Syndrome). To support the treatment of successful treatment of sepsis antibiotic therapy is used. In the selection of antibiotics, several things need to be considered in order to avoid resistance and mortality risk. This study aims to determine the characteristics and use of antibiotics in septic patients at Abdul Wahab Sjahranie Hospital. The research method was used a non-experimental study with a descriptive design. Data retrieval was carried out retrospectively with subjects from medical record data on septic patients at Abdul Wahab Sjahranie Hospital. The results showed that the highest sepsis sufferers based on sex were women (55\%), based on age were the age group 45-64 years (73.33\%), based on work were housewives (36.66\%) and based on inpatient rooms were spaces class III care (60\%). $40 \%$ of the study subjects used single antibiotics and $60 \%$ used combination antibiotics.
\end{abstract}

Keywords: Antibiotics, Patient Characteristics, Sepsis

\begin{abstract}
ABSTRAK
Sepsis merupakan kondisi medis yang ditandai dengan adanya peradangan di seluruh tubuh sebagai respon terhadap infeksi yang disebabkan oleh keadaan SIRS (Systemic Inflammatory Response Syndrome). Untuk menunjang terapi keberhasilan pengobatan penyakit sepsis digunakan terapi antibiotik. Dalam pemilihan antibiotik perlu diperhatikan beberapa hal guna menghindari resistensi dan resiko mortalitas. Penelitian ini bertujuan untuk mengetahui karakteristik dan penggunaan antibiotik pada pasien sepsis di Rumah Sakit Abdul Wahab Sjahranie. Metode penelitian yang digunakan adalah studi non eksperimental dengan rancangan deskriptif. Pengambilan data dilakukan secara retrospektif dengan subjek dari data rekam medik pasien sepsis di Rumah Sakit Abdul Wahab Sjahranie. Hasil penelitian menunjukkan bahwa penderita sepsis tertinggi berdasarkan jenis kelamin adalah perempuan (55\%), berdasarkan usia adalah kelompok usia 45-64 tahun (73,33\%), berdasarkan pekerjaan adalah ibu rumah tangga $(36,66 \%)$ dan berdasarkan ruang rawat inap adalah ruang rawat kelas III (60\%). Sebanyak $40 \%$ subjek penelitian menggunakan antibiotik tunggal dan $60 \%$ menggunakan antibiotik kombinasi.
\end{abstract}

Kata Kunci: Antibiotik, Karakteristik pasien, Sepsis 


\section{PENDAHULUAN}

Sepsis didefinisikan sebagai suatu keadaan disfungsi organ yang mengancam nyawa disebabkan oleh respon penjamu pasien yang tidak teregulasi terhadap infeksi [1]. Sepsis adalah masalah kesehatan baik di negara maju dan negara berkembang dan merupakan salah satu penyebab utama kematian terutama pada penderita di unit perawatan intensif ${ }^{[2]}$.

Angka kejadian sepsis di Amerika Serikat sekitar 300.000-500.000 kasus per tahun dan memiliki angka mortalitas sekitar 15\%-60\% ${ }^{[3]}$. Di Indonesia, angka kematian akibat sepsis mencapai $84,5 \%$ pada tahun 2000 di Rumah Sakit Cipto Mangunkusumo ${ }^{[4]}$. Selain itu, kejadian sepsis di RSUP Djamil Padang juga telah meningkat hampir $50 \%$ pertahunnya sejak tahun 2010 hingga Agustus $2013^{[5]}$.

Antibiotik merupakan terapi utama pada penderita sepsis ${ }^{[6]}$. Antibiotik merupakan obat yang paling banyak digunakan di dunia terkait banyaknya penyakit infeksi bakteri ${ }^{[7]}$. Dalam pemilihan antibiotik perlu diperhatikan beberapa hal yakni faktor spesifik pasien, faktor organisme penyebab, aspek farmakokinetik, farmakodinamik, keamanan, biaya dan manfaat guna menghindari resistensi, peningkatan biaya perawatan, dan resiko mortalitas [5]. Apabila resistensi antibiotik terus berkembang dan tersebar luas, maka dunia akan kembali ke masa sebelum ditemukannya antibiotik (pre antibiotic era ${ }^{[8]}$.

Tujuan dari penelitian ini adalah untuk mengetahui karakteristik pasien dan penggunaan antibiotik pada pasien sepsis di Rumah Sakit Abdul Wahab Sjahranie

\section{METODE}

Penelitian ini adalah studi non eksperimental dengan rancangan deskriptif. Penelitian dilakukan secara retrospektif menggunakan data rekam medik pasien sepsis di Rumah Sakit Abdul Wahab Sjahranie periode 2017. Pengambilan data dilakukan pada bulan Agustus-November 2018. Kriteria inklusi penelitian ini adalah pasien sepsis yang dirawat inap pada periode 2017, pasien sepsis yang berusia lebih dari 18 tahun, pasien sepsis yang menggunakan terapi antibiotik dan pasien dengan rekam medis yang lengkap meliputi identitas pasien, diagnosis, pemeriksaan fisik, dan profil penggunaan antibiotik.

\section{HASIL DAN PEMBAHASAN}

Penelitian ini dilakukan dengan mengambil data pada rekam medik pasien sepsis di Rumah Sakit Abdul Wahab Sjahranie periode 2017. Jumlah sampel pasien yang dilibatkan dalam penelitian ini sebanyak 60 pasien.

Tabel 1. Tabel Distribusi Jenis Kelamin Pasien Sepsis di Rumah Sakit Abdul Wahab Sjahranie periode 2017

\begin{tabular}{ccc}
\hline Jenis Kelamin & Jumlah $(\mathrm{n}=60)$ & Presentase $(\%)$ \\
\hline Laki-laki & 27 & $45 \%$ \\
Perempuan & 33 & $55 \%$ \\
\hline Total & 60 & $100 \%$ \\
\hline
\end{tabular}


Tabel 2. Tabel Distribusi Usia Pasien Sepsis di Rumah Sakit Abdul Wahab Sjahranie periode 2017

\begin{tabular}{ccc}
\hline Usia & Jumlah $(\mathrm{n}=60)$ & Presentase $(\%)$ \\
\hline $1-4$ tahun & 0 & $0 \%$ \\
$5-14$ tahun & 0 & $0 \%$ \\
$15-24$ tahun & 3 & $5 \%$ \\
$25-44$ tahun & 7 & $11,67 \%$ \\
$45-64$ tahun & 44 & $73,33 \%$ \\
$>65$ tahun & 6 & $10 \%$ \\
\hline Total & 60 & $100 \%$
\end{tabular}

Tabel 3. Tabel Distribusi Pekerjaan Pasien Sepsis di Rumah Sakit Abdul Wahab Sjahranie periode 2017

\begin{tabular}{ccc}
\hline Pekerjaan & Jumlah $(\mathrm{n}=60)$ & Presentase $(\%)$ \\
\hline IRT & 22 & $36,66 \%$ \\
Swasta & 21 & $35 \%$ \\
PNS & 3 & $5 \%$ \\
Nelayan & 1 & $1,67 \%$ \\
Buruh & 2 & $3,33 \%$ \\
Wiraswasta & 4 & $6,67 \%$ \\
Pensiunan PNS & 2 & $3,33 \%$ \\
Petani & 1 & $1,67 \%$ \\
Lain-lain & 4 & $6,67 \%$ \\
\hline Total & 60 & $100 \%$
\end{tabular}

Tabel 4. Tabel Distribusi Ruang Rawat Inap Pasien Sepsis di Rumah Sakit Abdul Wahab Sjahranie periode 2017

\begin{tabular}{ccc}
\hline Ruangan & Jumlah $(\mathrm{n}=60)$ & Presentase $(\%)$ \\
\hline Paviliun & 9 & $15 \%$ \\
Ruang Rawat I & 7 & $11,67 \%$ \\
Ruang Rawat II & 8 & $13,33 \%$ \\
Ruang Rawat III & 36 & $60 \%$ \\
\hline Total & 60 & $100 \%$ \\
\hline
\end{tabular}

Tabel 1 menunjukkan karakteristik pasien berdasarkan jenis kelamin diperoleh presentase kejadian sepsis pada laki-laki $(45 \%)$ dan perempuan $(52 \%)$ dari total 60 pasien sepsis. Data menunjukkan bahwa angka kejadian sepsis lebih banyak terjadi pada perempuan dibandingkan laki-laki. Dalam beberapan pentian dikemukakan bahwa laki-laki memiliki hormon androgen yang mampu menjadi penekan pada sel yang diperantarai oleh sistem imun, sedangkan pada wanita memiliki efek protektif sebagai perlindungan pada kondisi sepsis. Perbedaan jenis kelamin ini mungkin hanya terbukti pada pasien yang lebih muda dari 50 tahun, menunjukkan bahwa 
wanita pasca menopause tidak lagi dalam kondisi protektif terhadap sepsis ${ }^{[9]}$. Selain itu hasil ini dapat disebabkan oleh salah satu kemungkinan yakni lebih banyaknya penderita perempuan yang immunokompromis dibanding laki-laki [10]

Tabel 2 menunjukkan bahwa karakteristik pasien berdasarkan umur diperoleh presentase kejadian sepsis tertinggi pada rentang usia 45-64 tahun sebesar $(73,33 \%)$ dibandingkan kelompok rentang usia lainnya. Seiring bertambahnya usia maka terjadi penurunan fungsi dari beberapa organ tubuh ${ }^{[11]}$. Orang yang lebih tua memiliki proporsi yang lebih besar (58-65\%) pada pasien sepsis. Selain itu angka insiden dan tingkat kematian secara signifikan lebih besar pada usia lanjut ${ }^{[12]}$.

Tabel 3 menunjukkan bahwa karakteristik pasien berdasarkan pekerjaan diperoleh kejadian sepsis tertinggi pada ibu rumah tangga dengan presentase sebesar $(36,66 \%)$ dibandingkan kelompok pekerjaan lainnya. Hasil ini dapat disebabkan karena pekerjaan domestik ibu rumah tangga banyak melibatkan keadaan panas dan lembab, dimana dua hal ini merupakan suasana berkembang biak yang baik untuk jamur [13]. Jamur merupakan salah satu mikrooganisme yang dapat menyebabkan sepsis.

Tabel 4 menunjukkan bahwa karakteristik pasien berdasarkan ruang rawat inap diperoleh kejadian sepsis tertinggi terjadi pada ruang rawat inap kelas III dengan presentase sebesar $(60 \%)$ dibandingkan ruang rawat inap lainnya. Hal ini dapat disebabkan oleh salah satu kemungkinan yaitu banyaknya pengunjung di ruang rawat inap kelas III.
Banyaknya pengunjung dapat menjadi penyebab kejadian infeksi nosokomial, karena kuman yang dibawa oleh pengunjung dapat menyebar ke pasien, terlebih jika pengunjung sedang terinfeksi suatu penyakit tertentu ${ }^{[14]}$. Tempat perawatan secara tidak langsung berpengaruh terhadap terjadinya peningkatan mortalitas, pada umumnya resiko mortalitas terjadi pada pasien sepsis berat dan syok sepsis yang mendapatkan infeksi akibat health care/ hospital acquired infection ${ }^{[11]}$.

Tabel 5 menunjukkan profil pengobatan berupa penggunaan antibiotik monoterapi dan kombinasi pada pasien sepsis di rumah sakit Abdul Wahab Sjahranie. Data menunjukkan antibiotik monoterapi yang paling banyak digunakan pasien sepsis adalah antibiotik golongan sefalosporin generasi ketiga yaitu Ceftriaxone dengan presentase sebesar (21,66\%). Ceftriaxone memiliki spektrum aktivitas luas yang bekerja dengan menghambat dinding sel mikroba dan merupakan salah satu antibiotik yang tidak menstimulasi pelepasan lipopolisakarida sehingga tidak memperburuk keadaan pasien [15]. Penggunaan Ceftriaxon yang tinggi kemungkinan disebabkan karena memiliki kelebihan waktu paruh eliminasi yang panjang, sehingga memungkinkan diberikan satu kali sehari [16]. Selain itu data menunjukkan antibiotik kombinasi yang paling banyak digunakan adalah Ceftriaxone dengan Metronidazole dengan presentase sebesar $(16,66 \%)$. Beberapa pasien menggunakan terapi dengan kombinasi beta-laktam/ sefalosporin dan metronidazole sebagai terapi antibiotik aerob dan anaerob ${ }^{[17]}$. 
Tabel 5. Profil Penggunaan Antibiotik Pasien Sepsis di Rumah Sakit Abdul Wahab Sjahranie Periode 2017

\begin{tabular}{|c|c|c|}
\hline Antibiotik Monoterapi & Jumlah (n=60) & Presentase $(\%)$ \\
\hline $\mathrm{CPR}$ & 2 & $3,33 \%$ \\
\hline CPS & 2 & $3,33 \%$ \\
\hline CFT & 13 & $21,66 \%$ \\
\hline DRP & 1 & $1,67 \%$ \\
\hline MRP & 4 & $6,67 \%$ \\
\hline AMK & 1 & $1,67 \%$ \\
\hline MRN & 1 & $1,67 \%$ \\
\hline Total & 24 & $40 \%$ \\
\hline \multicolumn{3}{|l|}{ Antibiotik Kombinasi } \\
\hline CFT dengan MTD & 10 & $16,66 \%$ \\
\hline CFT dengan MRP & 3 & $5 \%$ \\
\hline CTX dengan MRP & 1 & $1,67 \%$ \\
\hline MTD dengan SGT & 1 & $1,67 \%$ \\
\hline CPS dengan BQF & 1 & $1,67 \%$ \\
\hline CFT dengan CPR & 3 & $5 \%$ \\
\hline MTD dengan MRP & 2 & $3,33 \%$ \\
\hline CPR dengan LVF & 1 & $1,67 \%$ \\
\hline Total & 22 & $36,67 \%$ \\
\hline \multicolumn{3}{|l|}{ Antibiotik Kombinasi } \\
\hline CFT dengan MTD IMP & 1 & $1,67 \%$ \\
\hline CFT dengan MTD MRP & 1 & $1,67 \%$ \\
\hline CFT dengan CFX MTD & 2 & $3,33 \%$ \\
\hline CFT dengan MTD CPR & 2 & $3,33 \%$ \\
\hline CFT dengan MTD LVF & 1 & $1,67 \%$ \\
\hline CFT dengan CFX CTX & 1 & $1,67 \%$ \\
\hline Total & 8 & $13,33 \%$ \\
\hline \multicolumn{3}{|l|}{ Antibiotik Kombinasi } \\
\hline CFT dengan MTD MRP CFX & 1 & $1,67 \%$ \\
\hline CFT dengan MTD MRN MRP & 1 & $1,67 \%$ \\
\hline CFT dengan MTD CPR CFX & 1 & $1,67 \%$ \\
\hline CFT dengan LVF MTD MRP & 1 & $1,67 \%$ \\
\hline CFT dengan MTD AMK LVF & 1 & $1,67 \%$ \\
\hline Total & 5 & $8,33 \%$ \\
\hline \multicolumn{3}{|l|}{ Antibiotik Kombinasi } \\
\hline CFT dengan CTX MTD TCZ CLS & 1 & $1,67 \%$ \\
\hline Total & 1 & $1,67 \%$ \\
\hline
\end{tabular}

Keterangan: CPR: Ciprofloxacin; CFT: Ceftriaxone; DRP: Doripenem; MRP: Meropenem; CPS: Cefoperazone Sulbactam; AMK: Amikasin; MRN: Merosan; MTD: Metronidazole; CTX: Cefotaxime; SGT: Sagestam; BQF: Baquinor Forte; LVF: Levofloxacin; IMP: Imipenem; CFX: Cefixime; TCZ: Trichodazol; CLS: Claneksi.

\section{KESIMPULAN}

Hasil penelitian menunjukkan bahwa karakteristik pasien tertinggi berdasarkan jenis kelamin adalah perempuan $(55 \%)$, berdasarkan usia adalah rentang usia 45-64 tahun $(73,33 \%)$, berdasarkan pekerjaan adalah IRT $(36,66 \%)$ dan berdasarkan ruang 
rawat inap adalah ruang rawat inap kelas III (60\%). Sebanyak 40\% subjek penelitian menggunakan antibiotik tunggal dan $60 \%$ menggunakan antibiotik kombinasi. Profil penggunaan antibiotik menunjukkan antibiotik monoterapi yang paling banyak digunakan adalah Ceftriaxone $(21,66 \%)$ dan antibiotik kombinasi yang paling banyak digunakan adalah Ceftriaxone dengan Metronidazole $(16,66 \%)$.

\section{DAFTAR PUSTAKA}

[1] Wulandari, Anindita., Sri Martuti., Pudjiastuti. 2017. Perkembangan Diagnosis Sepsis pada Anak. Sari Pediatri. Vol. 19 No. 4.

[2] Oematan, Yosef., Jeanette I. Ch. Manoppo., Ari L. Runtunuwu. 2009. Peran Inflamasi dalam Patofisiologi Sepsis dan Syok Septik pada Anak. Jurnal Biomedik. Vol. 1 No. 3.

[3] Southwick, Frederick S. 2004. Infectious Diseases: A Clinical Short Course Second Edition. The McGraw-Hill Medical Publishing Division. USA.

[4] Sukrisman L., Tambunan KL., Suhendro., Sukmana N. 2004. Diagnosis of disseminated intravascular coagulation in sepsis scoring system of a thrombosishemostatis center. Acta Med Indones-Indones $J$ Intern Med. Volume 36 Number 1.

[5] Astutik, Arwin Widi., Nurul Annisa., Rolan Rusli., Arsyik Ibrahim. 2017. Kajian Kesesuaian Pemilihan Antibiotik Empiris pada Pasien Sepsis di Instalasi Rawat Inap RSUD Abdul Wahab Sjahranie. Proceeding of the $5^{\text {th }} \quad$ Mulawarman Pharmaceuticals Conferences, Fakultas Farmasi Universitas Mulawarman, Samarinda, 23-24 April 2017.

[6] Romdhoni, Achmad C. 2009. SIRS/ Sepsis dan Syok Septik pada Penderita Tumor Ganas Kepala dan Leher. Jurnal THT-KL. Vol.2 No.1.
[7] Musdalipah., Muh. Azdar Setiawan., Eria Santi. 2018. Analisis Efektivitas Biaya Antibiotik Sefotaxime ddan Gentamisin Penderita Pneumonia pada Balita di RSUD Kabupaten Bombana Provinsi Sulawesi Tenggara. Jurnal Ilmiah Ibnu Sina. Vol.3 No.1.

[8] Rustam I. 2010. A Brief of The Antibiotic Era: Lesson Learned and Challenges for The Future. Frontiers In Microbiology. Volume 1.

[9] Angele., Pratschke., Hubbard., Chaudry. 2014. Gender Differences in Sepsis. Cardiovascular and Immmunological Aspects. Virulence. Volume 5, Number 1.

[10] Irawan, Danny., Hamidah., Purwati., Triyono EA., Bramantono., Arfianto V., Hadi U., Nasronudin, Suharto., Soewandojo E. 2012. Profil Penderita Sepsis Akibat Bakteri Penghasil ESBL. $J$ Peny Dalam. Vol. 13 No. 1.

[11]Katu, Sudirman., Suhendro S., Herdiman TP., Murdani A. 2015. Faktor-Faktor yang Mempengaruhi Keberhasilan Terapi Antibiotik Empirik pada Pasien Sepsis Berat dan Syok Sepsis di Bangsal Rawat Inap Penyakit Dalam Rumah Sakit Cipto Mangunkusumo. Jurnal Penyakit Dalam Indonesia. Vol. 2 No. 2.

[12] Starr, ME., Hiroshi S. 2014. Sepsis in Old Age: Review of Human and Animal Studies. Aging and Disease. Volume 5, Number 2.

[13] Sondakh, Cyndi E.E.J., Thigita A Pandaleke., Ferra O. Mawu. 2016. Profil dermatofitosis di Poliklinik Kulit dan Kelamin RSUP Prof. Dr. R. D. Kandou Manado periode Januari - Desember 2013. Jurnal eClinic (eCl). Volume 4, Nomor 1.

[14] Nugraheni. Ratna., Suhartono., Sri Winarni. 2012. Infeksi Nosokomial di RSUD Setjonegoro Kabupaten Wonosobo. Media Kesehatan Masyarakat Indonesia. Vol. 11 No. 1. 
Karakteristik dan Penggunaan Antibiotik Pasien Sepsis di Rumah Sakit Abdul Wahab Sjahranie Periode 2017

[15] Hidayati., Helmi A., Raveinal. 2016. Kajian Penggunaan Antibiotik pada Pasien Sepsis dengan Gangguan Ginjal. Jurnal Sains Farmasi \& Klinis. Vol. 02 No. 02.

[16]Wiryalie, Linggawati. 2017. Ceftriaxone-Hospital Pack. $C D K$ 250. Vol.44 No.3
[17] Sodik DC., Pradipta IS., Lestari K. 2012. Pola Penggunaan Antibiotik dan Pola Kuman pada Pasien Sepsis Rawat Inap RSUP Dr. Hasan Sadikin Bandung (Skripsi). Jatinangor: Universitas Padjajaran. 